\title{
Tuberkulosiaren intzidentzia eta desparekotasun soziala Gipuzkoan, 2010-2017 denboraldian
}

\section{Tuberculosis incidence and social inequalities in Gipuzkoa, 2010-2017}

Amaia Soraluce Olañeta ${ }^{1^{*}}$, Liher Imaz Goienetxea ${ }^{1,2}$, Asier Anabitarte Riol ${ }^{2,3}$, Lorea Alvarez Guerrico $^{1}$, Rosa Sancho Martínez ${ }^{1,2}$, Edurne Bikuña Ugarte ${ }^{4}$, Mikel Basterrechea Irurzun $^{1,2}$

\author{
${ }^{1}$ Eusko Jaurlaritzako Osasun Saila, Gipuzkoako Osasun Publikoaren Zuzendariordetza \\ ${ }^{2}$ Biodonostia Osasun Ikerketa Institutua \\ ${ }^{3}$ Euskal Herriko Unibertsitatea (UPV/EHU), Medikuntza eta Erizaintza Fakultatea, Leioa. \\ ${ }^{4}$ Osakidetza, Zumarragako Ospitalea, Tuberkulosiaren kudeatzailea \\ *a-soraluceolaneta@euskadi.eus
}

\section{Laburpena}

Gauza jakina da gizarte-faktore desberdinek zenbait gaixotasunen intzidentzia eta eboluzioa baldintzatzen dutela, mundu-mailan zein EAEn. Lan honen helburu nagusia Gipuzkoan 2010-2017 denboraldian maila sozioekonomikoaren eta betidanik pobreziarekin erlazionatutako gaitz baten arteko lotura aztertzea izan da; alegia, gabezia-mailaren eta tuberkulosiaren arteko harremana ikertzea. Bigarren helburua 2003-2017 urteetan zehar gaixotasun horren eboluzioa deskribatzea izan da. Maila sozioekonomikoa analizatzeko, paziente bakoitzari modu ekologikoan esleitutako gabeziaindizea erabili da, diagnostiko aldian bizi ziren errolda-sekzioko informazioaz baliatuta. Intzidentzien kalkulurako, 2011ko erroldatik lortu da biztanle kopurua, sekzio bakoitzeko eta adinaren zein sexuaren arabera, eta urte bereko EAEko populazioa erabilita estandarizazioa egin da. Biriketako lokalizazioa zuten kasuetan, maila sozioekonomikoa diagnostikoaren atzerapenarekin eta tratamendua betetzearekin elkarturik ote dagoen ere ikertu da. Horretarako hainbat analisi estatistiko erabili dira, SPSS programaz baliatuz. Lortutako emaitzei so eginez, Gipuzkoan tuberkulosiaren intzidentzia ekologikoki esleitutako gabezia-mailarekin elkarturik dagoela ondoriozta daiteke. Izan ere, maila sozioekonomiko baxuenean kokatzen diren pertsonek maila altuenean daudenek baino tuberkulosia izateko arrisku handiagoa dutela ikusi da; arriskuaren igoera estatistikoki esangarria izanik gizonetan (tasa estandarizatuaren arrazoia: 2,15, konfiantza-tartea: 1,51-3,07). Hala ere, azken 15 urteetan maila sozioekonomikoen arteko desberdintasunak murriztu direla ikus daiteke. Osasun-arretari dagokionez, ez da maila sozioekonomikoaren eta diagnostikoaren atzerapenaren arteko erlaziorik aurkitu; bai, ordea, tratamendua betetzearekin, gabezia-maila baxuetan tratamendua betetzeko probabilitatea txikiagoa izanik.

Gako-hitzak: tuberkulosia, gabezia-maila, intzidentzia, gipuzkoa 


\section{Abstract}

It has been described that social factors alter the incidence and evolution of several illnesses, not only globally, but also in the Basque Country. The main goal of this research work was to analyse whether socioeconomic situation is associated with tuberculosis, which has been historically linked to poverty. To this end, data from Gipuzkoa was used, taking into consideration 2010-2017 period of time. A secondary objective was to describe the evolution of tuberculosis in Gipuzkoa, from year 2003 to 2017. In order to analyse socioeconomic status, each case was assigned to a level of deprivation using an ecological method, considering their census information when the diagnostic was made. Incidence was calculated using census data from 2011, discerning between section, age and sex. Basque Country's population data from the same year was used to obtain standardised rates. In those cases with pulmonary tuberculosis, diagnostic delay and adherence to treatment were studied for different levels of deprivation. Statistical analyses were performed by SPSS program. An association between tuberculosis incidence and ecologically assigned socioeconomic situation has been observed, since a greater risk of suffering from tuberculosis has been detected in people with the higher level of deprivation when comparing with that of the lower one, being differences statistically significant in men (standardized incidence ratio: 2.15, confidence interval: 1.51-3.07). Nevertheless, differences among socioeconomic status have been reduced in the last 15 years. Regarding health care, no association between diagnostic delay and socioeconomic situation has been described. However, adherence to treatment is more difficult to fulfill in more deprived populations.

Keywords: tuberculosis, deprivation, incidence, gipuzkoa

Bidalia: 2019ko uztailaren 15ean.

Onartua: 2019ko azaroaren 26an.

http://doi.org/10.26876/osagaiz.2.2019.265

\section{Sarrera}

Osasunarekin erlazionaturiko hainbat arazo eta garaiz aurreko hilkortasuna, gizarte-faktore desberdinek baldintzatzen dituzte; hala nola ikasketa-mailak, lanak eta lan-baldintzek, diru-sarrerek, bizi-baldintzek edota gizarte-bazterketak $(1,2)$. Faktore horiek guztiek osasun-sistemaren berariazko eskuduntzak gainditzen dituzte. Hori aintzat hartuta, eta osasunari eragiten dioten alderdi ugariak jorratzeak dakarren erronkari erantzuteko, 2013-2020 Euskadiko Osasun Planaren (3) bost printzipio nagusien artean ekitatea sartu zen. Horren helburu nagusia hau litzateke: sozialki, ekonomikoki, demografikoki edo geografikoki zehaztutako biztanle-taldeen artean gaixotasuneko eta osasuneko alde sistematiko eta saihesgarririk ez egotea bermatzea. Izan ere, ezaguna da mundu-mailan ez ezik, Euskal Autonomia Erkidegoan (EAEn) ere, egoera sozioekonomiko desberdina duten pertsonen artean desberdintasun sistematikoak antzematen direla gaixotasun kronikoen eta kutsakorren intzidentzian zein hilkortasunean (4-8).

Pobreziarekin erlazionaturiko gaixotasun infekziosoen artean tuberkulosia da ezagunenetariko bat (9). Mycobacterium tuberculosis deritzon bazilo batek eragiten du eta airetik transmititzen da, kutsakorra den pertsonak eztula edo doministiku egitean. Gehienetan birikei eragiten die (biriketako tuberkulosia), nahiz eta gorputzeko beste organo edo lokalizazioetan topatu daitekeen ere (10).

Tuberkulosia mundu-mailan heriotza gehien eragiten duten lehengo 10 zergatien artean kokatu zen 2017. urtean. Osasunaren Mundu Erakundearen (OMEren) arabera urte horretan 10 milioi kasu berri eta 1,6 milioi heriotza eragin zituen. Gaitz honek ez die berdin eragiten lurralde guztiei, ezta egoera sozioekonomiko desberdina duten pertsonei ere. Esaterako, aipaturiko 2017ko 10 milioi kasu berrietatik, bi heren munduko zortzi herrialdetan gertatu ziren: India (\% 27), Txina (\% 9), Indonesia (\% 8), Filipinak (\% 6), Pakistan (\% 5), Nigeria (\% 4), Bangladesh (\% 4) eta Hegoafrika (\% 3) (10Errorea! Laster-marka definitu gabe.). Herrialde garatuei dagokienez, oro har, intzidentzia altuagoak 
antzematen dira atzerrian jaiotako pertsonetan edota maila sozioekonomiko baxuagoa dutenetan (11-14).

Hiru lurralde historikoetako Epidemiologia Unitateek 2003-2009 denboraldiko datuekin egindako ikerketa batean, EAEn tuberkulosiaren intzidentziaren eta egoera sozioekonomikoaren arteko asoziazioa aurkitu zuten (argitaratu gabeko datuak). Osasun-estaldura unibertsala duen gizarte honetan, erlazio horren eboluzioa aztertzea garrantzitsua da, egoera ekonomiko orokorrak duen eragina ikertzeko helburuz.

Horiek horrela, ikerlan honen helburu nagusia 2010-2017 denboraldian maila sozioekonomikoaren eta tuberkulosiaren intzidentziaren arteko erlazioa aztertzea da, Gipuzkoan bizi diren gizonezkoetan eta emakumezkoetan. Gainera, egoera sozioekonomikoek diagnostikoaren atzerapenean edota tratamendua betetzean eragina duten analizatuko da. Azkenik, gaixotasun honen intzidentziaren eboluzioa ere aztertuko da 2003 eta 2017 urteetan zehar, gabezia-maila desberdinentzat.

\section{Metodoa}

Zeharkako ikerketa bat burutu da, Gipuzkoan 2010-2017 denboraldian tuberkulosiaren intzidentzia aztertzeko.

\subsection{Ikertutako populazioa eta datuen iturria}

Azterlan honetan 2010 eta 2017 bitartean Gipuzkoako Erakunde Sanitario Integraturen batean bizi ziren pertsonen tuberkulosi-diagnostikoak hartu dira kontuan. Datuok EAEko nahitaez aitortu beharreko gaixotasunen (ABG) erregistrotik bildu dira. Azken horrek, zehaztasunik onena bermatzeko asmoz, bilaketa aktiboa sustatzen du 1995az geroztik. Ikertutako kasuen aldagaiak hurrengoak izan dira: sexua, adina, bizitokiaren posta-helbidea, jaioterria, gaixotasunaren lokalizazioa, diagnostikoaren atzerapena (lehenengo sintomak garatzen direnetik tratamendua hartzen hasi arte igarotako denbora) eta tratamenduaren betetze-maila.

\subsection{Maila sozioekonomikoa}

Maila sozioekonomikoa aztertzeko, paziente bakoitzari modu ekologikoan esleitutako gabeziaindizea erabili da, diagnostiko aldian bizi ziren errolda sekzioko informazioaz baliatuta.

Kasuen posta-helbidearen datuak erabiliz, NORA programarekin geoerreferentziazioa egin zen. Ondoren, dagokien 2011ko errolda-sekzioa esleitu zitzaien, ordukoa baita errolda-sekzioa eta gabezia-maila erlazionatzen dituen azken ikerketa. Era horretan, sekzio bakoitzaren gabeziaindizearen kalkulua Osasun Saileko Azterlan eta Ikerkuntza Sanitarioko Zerbitzuak egin zuen, MEDEA ikerketaren metodologia bera erabiliz (15). Horretarako, 2011ko erroldako bost adierazle sozioekonomiko eduki zituzten kontuan: langabezian dauden pertsona aktiboen ehunekoa, kualifikatu gabeko eskulangileen ehunekoa, behin-behineko soldatapekoen ehunekoa, lehen mailako ikasketak edo gutxiago dituzten pertsonen proportzioa, eta soilik lehen mailako ikasketak edo gutxiago dituzten gazteen ehunekoa (16-29 urte). Aldagai nagusien analisia eginda, errolda-sekzio bakoitzarentzat indize bat kalkulatu zuten. Ondoren, errolda-sekzioak indize horren arabera ordenatu zituzten, eta bost kintiletan banandu. Era honetan, lehenengo kintila gabezia gutxien duten sekzioei dagokie (maila sozioekonomiko altuena); bosgarrena, aldiz, gabezia-maila altuena dutenei (maila sozioekonomiko baxuena).

Intzidentziaren kalkulurako, 2011ko erroldatik lortu da biztanle-kopurua, sekzio bakoitzeko eta adin zein sexuaren arabera. Maila sozioekonomiko desberdinen populazioa kalkulatzeko, kintil bakoitzari dagokion errolda-sekzioetako biztanleria hartu da aintzat.

\subsection{Analisi estatistikoa}

Bost gabezia-maila ezberdinetan aldagaien artean estatistikoki esanguratsuak diren desberdintasunak dauden ikertzeko, hainbat analisi estatistiko erabili dira. Alegia, khi karratuaren 

Guerrico, Rosa Sancho Martínez, Edurne Bikuña Ugarte, Mikel Basterrechea Irurzun

proba eta Fisher-en proba zehatza proportzioen konparaziorako (sexua, atzerrian jaiotakoak eta biriketako lokalizazioa aldagaientzat) eta Mann-Whitney-ren $U$ testa batez bestekoen konparaziorako (adinarentzat). Datuak IBM SPSS statistic ${ }^{\circledR}$ (25. bertsioa) (16) programarekin analizatu dira, $p<0,05$ balioak estatistikoki esanguratsutzat kontsideratuz.

Metodo zuzena erabiliz, eta erreferentzia moduan EAEko 2011ko biztanleria kontuan hartuta, denboraldi osorako tuberkulosiaren intzidentzia-tasa estandarizatua kalkulatu da kintil guztientzat, sexuaren araberako bereizketa eginez. Ondoren, lehenengo kintila erreferentzia moduan hartuta (gabezia sozial gutxieneko taldea) tasa estandarizatuen arrazoiak eta konfiantza-tarteak kalkulatu dira beste kintilentzat.

Osasun-sistemak maila sozioekonomikoaren araberako desberdintasunak aurkezten dituen aztertzeko, tuberkulosiaren diagnostikoaren atzerapenak eta tratamenduaren betetze zuzenak gabezia-mailarekin erlaziorik duten ikertu da. Lehenengoari dagokionez, biriketako lokalizazioa zuten kasuak soilik erabili dira analisia egiteko. Izan ere, gehien ematen den tuberkulosi mota izateaz gain, diagnostiko estandarizatuena duena ere bada. Hori dela-eta, tuberkulosiaren programan diagnostikoaren atzerapenaren kalkuluan kasu hauek bakarrik ebaluatzen dira.

Horiek horrela, maila sozioekonomikoaren eta diagnostikoaren atzerapenaren arteko erlazioa ikertzeko, lehenik eta behin Kaplan-Meier biziraupen-analisia egin da aldagai bakoitzarekin (sexua, adin-taldea eta atzerrian jaiotakoa izatea edo ez), banan-banan diagnostikoa egiteko denborarekin duten harremana aztertzeko. Ondoren, Cox-en biziraupen-analisia egin da, aldi berean gabeziaindizea eta aipatutako aldagaiek diagnostikoaren atzerapenean duten eragina ikertzeko.

Bestalde, biriketako tuberkulosia izan zuten kasuetan ere, khi karratuaren probaren bitartez, aldagai desberdinen eta tratamenduaren betetzearen arteko erlazioa aztertu da, jarraian, erlazioa erakutsi duten aldagaiak aintzat hartuta, erregresio logistikoaren bidez, gabezia-indizearen eta tratamenduaren betetzearen arteko erlazioa ikertzeko. Analisia egiteko hildako 58 pazienteak eta eragin desiragaitzak direla-eta tratamendua hartzeari utzi zioten bi pertsonak kendu dira. Izan ere, albo-ondorio horiek norbanakoen barne-faktoreek eragin zituztela kontsideratu da. Ondoren, bost gabezia-indizeak hiru taldetan birkodifikatu dira, tratamendua bete ez dutenetan lagin kopuru txikia dela-eta. Modu honetan, 1. eta 2. gabezia-indizeak 1. taldean multzokatu dira; 4. eta 5. indizeak, aldiz, 3. taldean.

2003-2017 denboraldian Gipuzkoako tuberkulosiaren intzidentzia-tasen eboluzioa aztertzeko, estandarizazio zuzenaren bitartez adinaren arabera doitutako tasak kalkulatu dira urte bakoitzeko eta bost gabezia-indize desberdinentzat. Populazio estandar moduan, 2011ko EAEko datuak erabili dira, eta erregresio-ereduen bitartez (Joinpoint) intzidentzia-tasen joera aztertu eta urteko aldaketaportzentajea (UAP) kalkulatu da $(17,18)$.

\section{Emaitzak}

2010-2017 denboraldian 991 tuberkulosi-kasu erregistratu ziren Gipuzkoan. Horietatik 557 gizonezkoak izan ziren eta 434, aldiz, emakumezkoak. Era honetan, urteko batez besteko tasa gordina 17,1/100 000 biztanleko izan zen populazio orokorrerako, 19,6/10 000 gizonetan eta $14,7 / 100000$ emakumeetan.

Kasuen \% 99,8ri (989/991) 2011ko erroldako sekzio bat esleitu ahal izan zitzaion. Esleipena ABGen erregistrotik lortutako georreferentziazio bidez burutu zen 895 kasutan. Beste 85 kasutan informazioa eskuz bilatu zen eta 9 pertsonari 5. gabezia-maila egokitu zitzaien, notifikazioan agertzen zen bizilekuaren ezaugarriak zirela-eta (eraikin hutsak, kalea edota kokaleku ezegonkorra).

Maila sozioekonomikoari buruzko informazioa lortu zen 989 kasuetatik 168 (\% 17,0) 1. gabeziamailan kokatu ziren, 252 (\% 25,4) 2. mailan, 260 (\% 26,2) 3. mailan, 192 (\% 19,4) 4. mailan eta beste $117 a k$ (\% 11,8a) 5. gabezia-mailan. Kasuen ezaugarriak, gabezia-mailaren arabera aztertuta, 1. taulan 
aurkezten dira. Ikus daitekeen moduan, ez dago desberdintasun esanguratsurik aztertutako lau aldagaien eta gabezia-mailen artean.

1. taula. Tuberkulosi-kasuen ezaugarriak gabezia-mailaren arabera. Gipuzkoa, 2010-2017.

\begin{tabular}{|c|c|c|c|c|c|c|c|}
\hline & \multicolumn{7}{|c|}{ Gabezia-maila } \\
\hline & Totala (\%) & 1 & 2 & 3 & 4 & 5 & $\mathbf{p}^{* *}$ \\
\hline Sexua & & & & & & & 0,112 \\
\hline Gizonezkoa & $556(56,2)$ & $91(54,2)$ & $139(55,2)$ & $135(51,9)$ & $114(59,4)$ & $77(65,8)$ & \\
\hline Emakumezkoa & $433(43,8)$ & $77(45,8)$ & $113(44,8)$ & $125(48,1)$ & $78(40,6)$ & $40(34,2)$ & \\
\hline Atzerrian jaioa & & & & & & & 0,134 \\
\hline Ez & $763(77,1)$ & $137(81,5)$ & $203(80,6)$ & $195(75,0)$ & $145(75,5)$ & $83(70,9)$ & \\
\hline Bai & $226(22,9)$ & $31(18,5)$ & $49(19,4)$ & $65(25,0)$ & $47(24,5)$ & $34(29,1)$ & \\
\hline Biriketako gaitza & & & & & & & 0,725 \\
\hline Ez & $355(35,9)$ & $56(33,3)$ & $89(35,3)$ & $98(37,7)$ & $74(38,5)$ & $38(32,5)$ & \\
\hline Bai & $634(64,1)$ & $112(66,7)$ & $163(64,7)$ & $162(62,3)$ & $118(61,5)$ & $79(67,5)$ & \\
\hline \multirow[t]{2}{*}{ Batez besteko adina (DE*) } & & & & & & & 0,195 \\
\hline & $50.4(20,5)$ & $51.5(20,6)$ & $51.4(20,2)$ & $50.8(20,5)$ & $50.3(20,3)$ & $46.2(20,7)$ & \\
\hline
\end{tabular}

*DE: Desbiderapen estandarra.

** p: p balioa, esangarritasun-maila.

Gabezia-maila guztietan gizonezkoen tasak emakumezkoenak baino altuagoak dira (2. taula), eta tasa horiek handituz doaz bi sexuetan maila sozioekonomiko altuenetik (1. kintila) baxuenera (5. kintila). Taula berean 2tik 5erako kintilen tasa estandarizatuen arrazoiak aurkezten dira, 1. gabezia-kintilaren tasarekin alderatuz lortzen direnak. Ikus daitekeenez, arrazoien balioak 1 baino handiagoak dira kintil guztietan. Hala ere, arriskuaren emendio hau estatistikoki esanguratsua da soilik 4. eta 5. mailetan gizonezkoen kasuan (\% 95 KTak 1,03-1,81 eta 1,51-3,07, hurrenez hurren) eta 3. mailan emakumezkoetan (\% 95 KT 1,02-1,80).

2. taula. Tuberkulosi-kasu kopurua, tasak eta tasa estandarizatuen arrazoia, gabezia-mailaren arabera.

Gipuzkoa, 2010-2017.

\begin{tabular}{|c|c|c|c|c|c|c|c|c|}
\hline \multirow[b]{2}{*}{ Gabezia-maila } & \multicolumn{4}{|c|}{ Gizonezkoak } & \multicolumn{4}{|c|}{ Emakumezkoak } \\
\hline & Kasu kop. & Tasa $^{a}$ & $T E^{b}$ & $\begin{array}{c}\text { TEA }^{\mathrm{c}} \text { (\% 95eko } \\
\text { KT) }\end{array}$ & Kasu kop. & Tasa $^{a}$ & $\mathrm{TE}^{\mathrm{b}}$ & $\begin{array}{c}\text { TEA }^{c} \text { (\% 95eko } \\
\text { KT) }\end{array}$ \\
\hline 1 (aberatsena) & 91 & 15,4 & 16,6 & 1 & 77 & 11,8 & 11,9 & 1 \\
\hline 2 & 139 & 18,3 & 19,3 & $1,16(0,89-1,51)$ & 113 & 14,5 & 14,4 & $1,21(0,91-1,62)$ \\
\hline 3 & 135 & 17,8 & 18,5 & $1,11(0,85-1,45)$ & 125 & 16,3 & 16,1 & $1,36(1,02-1,80)$ \\
\hline 4 & 114 & 22,2 & 22,8 & $1,37(1,03-1,81)$ & 78 & 15,0 & 14,9 & $1,25(0,91-1,72)$ \\
\hline 5 (pobreena) & 77 & 34.9 & 35,8 & $2,15(1,51-3,07)$ & 40 & 17,7 & 17,2 & $1,45(0,95-2,21)$ \\
\hline
\end{tabular}

${ }^{\mathrm{a}} 100.000$ biztanleko, tasa gordina.

${ }^{\mathrm{b}}$ TE: Tasa estandarizatua, 2011. urteko EAEko populazioaren adinaren arabera.

${ }^{\mathrm{C}}$ TEA: Tasa estandarizatuen arrazoia; KT: Konfiantza-tartea.

Emaitzak bere horretan mantentzen dira analisitik atzerrian jaiotako 226 kasuak kentzen direnean, baina esangura estatistikoa soilik gizonezkoen 5. kintilean mantentzen da (aurkeztu gabeko datuak).

Gaixotasunaren biriketako lokalizazioa duten kasuen artean diagnostikoaren atzerapenak ez du gabezia-mailarekin asoziaziorik erakusten, ez aldagai bakarreko analisian $(p=0,9)$ ez eta Cox-en biziraupen-analisia eginda ere.

Tratamenduaren betetze-mailari dagokionez, berriz, desberdintasunak antzeman dira. Izan ere, atzerrian jaiotakoen artean tratamenduaren betetze-maila baxuagoa dela ikusi da (\% 91,6 vs \% 98,8). Bestalde, aldagai hori erregresio logistikoan sartuta ere, gabezia-indizearen eta tratamendua betetzearen arteko erlazioa antzeman da ere. 
1. irudian ikusi daitekeen bezala, 2003-2017 denboraldian gabezia-maila guztietan tuberkulosiaren intzidentziaren jaitsiera estatistikoki esanguratsua eman da. Kasuak sexuaren arabera aztertuz gero, berriro ere intzidentziaren jaitsiera nabarmena da, gizonezkoen kasuan joera hori esanguratsua izanik (UAP: $-7,3$ ).

1. irudia. Tuberkulosiaren tasa estandarizatuen eboluzioa (Jointpoint) gabezia-mailaren arabera. Gipuzkoa, 2003-2017.

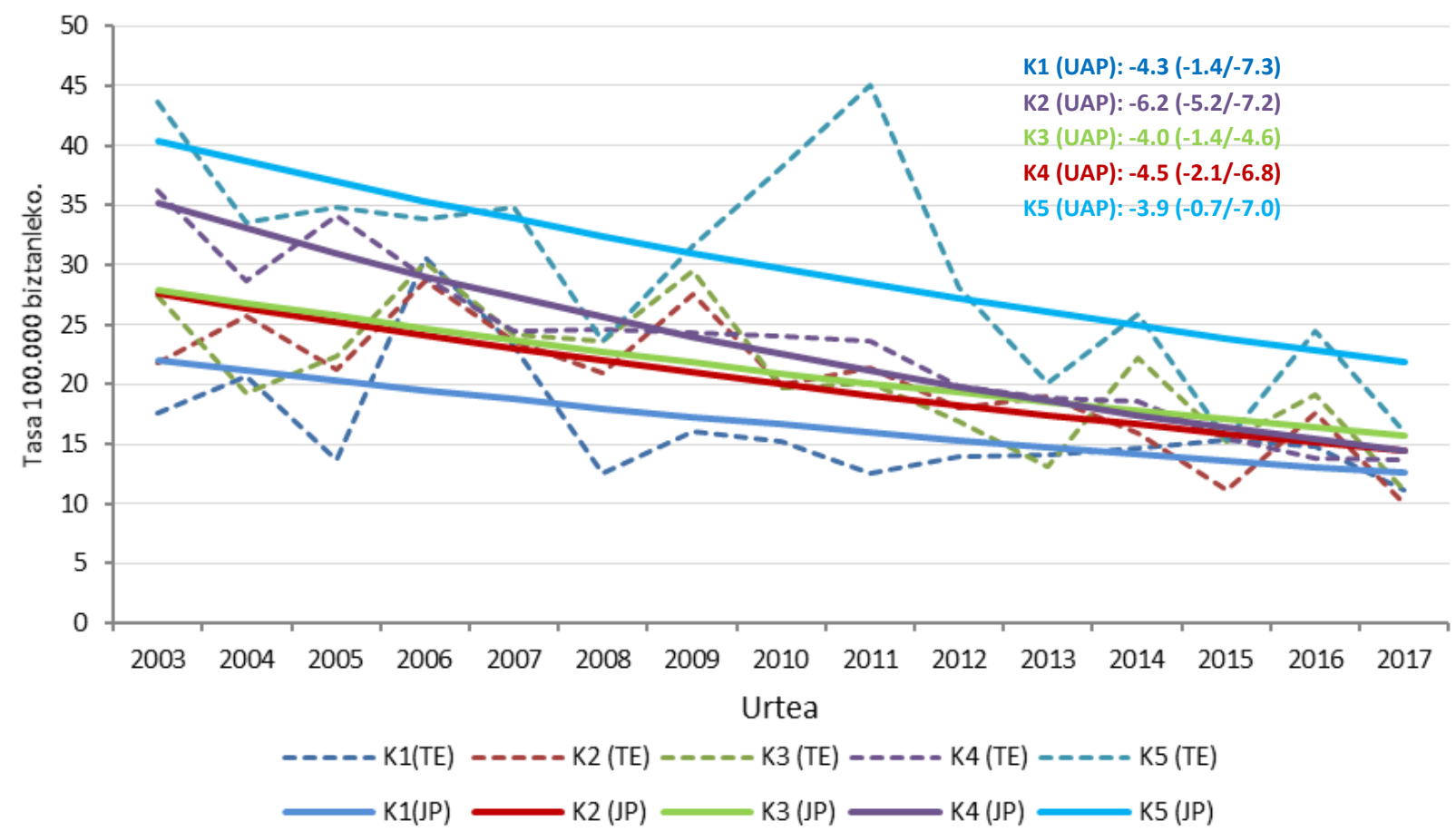

*K: Kintila; UAP: Urteko aldaketa-portzentajea; TE: Tasa estandarizatua, 2011. urteko EAEko populazioaren adinaren arabera; JP: Jointpoint

3. taulan aurkezten diren 2003. urteko tasa estandarizatuen arrazoiak 2017koekin alderatuz gero, ikusten da azterturiko lau kintiletan (2.etik 5.era, 1.a erreferentzia izanik) arrazoi hau gutxitu egin dela, jaitsiera handiena 4. eta 5. kintiletan eman delarik, (2,1etik 1,2ra eta 2,5etik 1,5era, hurrenez hurren).

3. taula. Tuberkulosi-kasu kopurua, tasa estandarizatua eta tasa estandarizatuen arrazoia gabezia-mailaren arabera. Gipuzkoa, 2003 eta 2017.

\begin{tabular}{l|cccc|cccc}
\hline & \multicolumn{3}{|c|}{$\mathbf{2 0 0 3}$} & \multicolumn{3}{c}{$\mathbf{2 0 1 7}$} \\
\hline Gabezia-maila & Kasu kop. & TE $^{\mathbf{a}}$ & TEA $^{\mathbf{b}}$ & \% 95eko KT & Kasu kop. & TE $^{\mathbf{a}}$ & TEA $^{\mathbf{b}}$ & \% 95eko KT \\
\hline $\mathbf{1}$ (aberatsena) & 24 & 17,6 & & & 17 & 11,1 & \\
$\mathbf{2}$ & 38 & 21,8 & 1,24 & $0,74-2,07$ & 19 & 10,1 & 0,91 & $0,47-1,75$ \\
$\mathbf{3}$ & 51 & 27,4 & 1,56 & $0,97-2,51$ & 21 & 11,2 & 1,01 & $0,53-1,91$ \\
$\mathbf{4}$ & 43 & 36,3 & 2,06 & $1,23-3,46$ & 18 & 13,7 & 1,23 & $0,63-2,40$ \\
$\mathbf{5}$ (pobreena) & 37 & 43,6 & 2,48 & $1,39-4,41$ & 9 & 16,1 & 1,45 & $0,60-3,47$ \\
\hline
\end{tabular}

${ }^{a}$ TE: Tasa estandarizatua, 2011. urteko EAEko populazioaren adinaren arabera

${ }^{\mathrm{b}}$ TEA: Tasa estandarizatuen arrazoia; KT: Konfiantza-tartea.

\section{Eztabaida}

Tuberkulosia pobreziarekin erlazionatu izan da historikoki, maila sozioekonomikoaren eta tuberkulosiaren arteko harremana aspaldian ezaguna izanik (19). Lan honetan lortutako emaitzei 
begiratuta, Gipuzkoan ere egoera hori ematen dela ondoriozta daiteke. Izan ere, maila sozioekonomiko baxuenean kokatzen diren pertsonek maila altuenean daudenek baino tuberkulosia izateko arrisku handiagoa dutela ikusten da, arriskuaren igoera esangarria izanik gizonezkoetan, baina ez emakumezkoetan. Azken horren arrazoia emakumezkoetan dagoen kasu-kopuru txikia izan daiteke.

Maila sozioekonomikoaren eta tuberkulosi-intzidentziaren arteko asoziazioa azal dezaketen mekanismoak konplexuak dira, eta norbanakoak eta testuinguru-faktoreak aintzat hartu behar dira. Testuingurukoei dagokienez, deskribatu izan da etxebizitzaren ezaugarriak eta bertan bizi diren pertsona kopurua tuberkulosi-arriskuarekin loturik daudela (20). Bestalde, banakako faktoreen artean, erretzeko ohitura tuberkulosiaren arrisku-faktore ezaguna da $(21,22)$. Tabakoa kontsumitzea norbanakoen faktorea izan arren, populazio batean dauden erretzaileen prebalentzia gabeziamailarekin erlazionatuta dagoela ere jakina da (7). Modu honetan, 2013ko EAEko Osasun Inkestaren arabera, tabako-kontsumoaren joera klase sozialaren eta ikasketa-mailaren araberakoa da: kontsumoak gora egiten du klase sozialak edo ikasketa-mailak behera egin ahala (45 urtetik gorako emakumezkoetan izan ezik) (23).

Migrazio-fenomenoek tuberkulosiaren intzidentziarekin, diagnostikoarekin eta tratamenduarekin erlazio estua dutela deskribatu da maiz $(24,25)$. Sarritan etorkinen kolektiboa maila sozioekonomiko baxuenetan kokatzen den arren, aipaturiko asoziazioa bere horretan mantentzen da analisitik atzerrian jaiotako kasuak kenduz gero, nahiz eta kasu gutxiago izatearen ondorioz emaitzek esangura-maila baxuagoa duten. Hortaz, lan honen arabera, gabezia-mailaren eta tuberkulosiaren intzidentziaren artean aurkituriko erlazioa migrazio-fenomenoarekiko independentea izango litzateke.

Zenbait ikerketak ondorioztatu dute atzerrian jaiotakoek eta maila sozioekonomiko baxuagoa duten pertsonek osasun-zerbitzuetara gutxiago jotzen dutela $(8,26-28)$, diagnostikoaren atzerapena ekar dezakeena. Hala ere, ikerketa honetan ez da diagnostikoaren atzerapenaren eta gabezia-mailaren zein jaioterriaren arteko erlaziorik antzeman. Horren zergatietako bat kolektibo hauetan tuberkulosiaren susmoa altuagoa dela izan daiteke, zeinak osasun-langileei diagnostiko azkar bat egitea errazten baitie. Gainera, beste lurralde batzuetan ez bezala, EAEko osasun-arreta unibertsala eta doakoa izateak eskuragarritasuna bermatzen du populazio osoan.

Aitzitik, gabezia-mailak tratamendua betetzea baldintzatzen duela ikusi da lan honetan, eta erlazio hori mantendu egiten da erregresio logistikoan jaioterria aintzat hartuta ere. Hau da, maila sozioekonomiko baxuagoa duten pazienteek probabilitate gutxiago izango dute tratamendua behar bezala betetzeko, beraien jaioterria dena delakoa izanda. Hainbat egilek deskribatu dute egoera irregularrean dauden etorkinek, etxerik gabekoek, droga-kontsumitzaileek edota egoera ekonomiko txarrean dauden pertsonek probabilitate baxuagoa dutela tratamendu farmakologikoak betetzeko (24). Atxikipen falta handitu daiteke tuberkulosia bezalako gaixotasunetan, non tratamenduak luzeak diren (hilabeteak) eta, ondorioz, eragin desiragaitzak agertzeko probabilitatea altua. Hala ere, kontuan izan behar da gure lanean tratamendua bete ez dutenen taldea, txikia izateaz gain, nahiko heterogeneoa dela. Horrela, askotan amaitu gabeko tratamendua kontsideratzen da pazientearen jarraipena egitea ezinezkoa den kasuetan, eta, ondorioz, atxikipena ezezaguna denean (adibidez, EAEtik kanpo bizitzera joan diren kasuak).

Gure lanean ikusi denez, 2017an tuberkulosiaren tasa estandarizatuen arrazoiak 2003an baino txikiagoak izan dira. Horrek adieraziko luke aztertutako denboraldiaren bukaeran gabezia-mailen arteko ezberdintasuna hasieran baino txikiagoa dela. Tuberkulosi kasuen jaitsiera populazioaren bizibaldintzen hobekuntzarekin erlazionatu da (29). Gaixotasun honekin lotutako zenbait arrisku-faktore 
Amaia Soraluce Olañeta, Liher Imaz Goienetxea, Asier Anabitarte Riol, Lorea Alvarez Guerrico, Rosa Sancho Martínez, Edurne Bikuña Ugarte, Mikel Basterrechea Irurzun

maila sozioekonomikoari elkarturik daude; esaterako, aurretik aipatutako tabakismoa edo alkoholkontsumoa (30). Azken urteetan tabako- eta alkohol-kontsumoek behera egin dute orokorrean, nahiz eta neurri ezberdinean adin-taldearen eta sexuaren arabera (23). Faktore horiek maila sozioekonomiko baxuagoko populazioan eragin handiagoa dutela kontuan izanda, aipaturiko jaitsierak aztertutako denboraldiaren amaieran ikusi den gabezia-mailen arteko desberdintasuna gutxitzen lagunduko luke hein batean.

Ikerketa honen mugetako bat maila sozioekonomikoaren egokitzapen ekologikoa da, zeina kasuaren errolda-sekzioaren arabera eta ez banakako informazioaren bitartez egin den. Hala ere, mota horretako adierazle sozioekonomikoen erabilera oso zabalduta dago honelako ikerketak egiterako orduan $(8,14,31)$, informazio hori modu indibidualean jasotzeko zailtasunak direla-eta. Beste muga bat gabezia-indizearen kalkulua izan daiteke. Aurretik aipatu den moduan, indize hori 2011ko datuekin kalkulatu zen; izan ere, 10 urtetik behin kalkulatzen da, aurrekoa 2001. urtekoa izanik. Lan honetan 2003-2017 denboraldiko datuak aztertu dira, eta denbora horretan sekzioren baten gabeziamaila aldatu bada, eragina izango luke lortutako emaitzetan.

\section{Ondorioak}

Lortutako emaitzen arabera, Gipuzkoan tuberkulosiaren intzidentzia ekologikoki esleitutako gabeziamailarekin elkarturik dago. Osasun-arretari dagokionez, ez da maila sozioekonomikoaren eta diagnostikoaren atzerapenaren arteko erlaziorik aurkitu; bai, ordea, tratamendua betetzearekin, gabezia-maila baxuetan tratamendua betetzeko probabilitatea txikiagoa delarik. Horrela, populazioaren bizi-baldintzak hobetuko lituzketen politikek, batez ere bazterturiko gizataldeei zuzendurikoek, tuberkulosiaren kontrolean eragina izango lukete.

\section{Bibliografia}

1. Marmot M, UCL Institute of Health Equity. Review of social determinants and the health divide in the WHO European Region [Internet]. Copenhagen: World Health Organization, 2013 [Kontsulta: 2019-07-01]. 190 or. Eskuragarri: http://www.euro.who.int/ data/assets/pdf file/0004/251878/Review-of-socialdeterminants-and-the-health-divide-in-the-WHO-European-Region-FINAL-REPORT.pdf.

2. Adler NE, Glymour MM, Fielding J. Addressing social determinants of health and health inequalities. JAMA. 2016 Urr 25; 316(16):1641-2.

3. Eusko Jaurlaritzako Osasun Saila (editorea). Osasuna, pertsonen eskubidea, guztion ardura: Euskadiko osasun politikak : Osasun Plana 2013-2020 = Políticas de salud para Euskadi: 20132020. Vitoria-Gasteiz: Eusko Jaurlaritzaren Argitalpen Zerbitzu Nagusia, 2014.

4. Esnaola S, Aldasoro E, Ruiz R, Audicana C, Pérez $Y$, Calvo $M$. Socioeconomic inequalities in mortality in the Basque Country (Spain). Gac Sanit. 2006; 20(1):16-24.

5. Larrañaga I, Arteagoitia JM, Rodríguez JL, González F, Esnaola S, Piniés JA. Sentinel Practice Network of the Basque Country. Socio-economic inequalities in the prevalence of Type 2 diabetes, cardiovascular risk factors and chronic diabetic complications in the Basque Country, Spain. Diabet Med. 2005; 22(8):1047-53. 
6. Orueta JF, Nuño-Solinís R, García-Álvarez A, Alonso-Morán E. Prevalence of multimorbidity according to the deprivation level among the elderly in the Basque Country. BMC Public Health. 2013 Urr 3; 13(918).

7. Bacigalupe A, Esnaola S, Martín U, Borrell C. Two decades of inequalities in smoking prevalence, initiation and cessation in a southern European region: 1986-2007. Eur J Public Health. 2013; 23(4):552-8.

8. Hurtado JL, Bacigalupe A, Calvo M, Esnaola S, Mendizabal N, Portillo I, Idigoras I, Millán E, Arana-Arri E. Social inequalities in a population based colorectal cancer screening programme in the Basque Country. BMC Public Health. 2015 Urr 5; 15(1021).

9. Creswell J, Jaramillo E, Lonnroth K, Weil D, Raviglione M. Tuberculosis and poverty: what is being done. Int J Tuberc Lung Dis. 2011; 15(4):431-2.

10. World Health Organization (editorea). Global tuberculosis report 2018. Genova: WHO, 2018.

11. LaFreniere M, Hussain H, He N, McGuire M. Tuberculosis in Canada, 2017. Can Commun Dis Rep. 2019 Ots 7; 45(2-3):67-74.

12. Apolinário D, Ribeiro AI, Krainski E, Sousa P, Abranches M, Duarte R. Tuberculosis inequalities and socio-economic deprivation in Portugal. Int J Tuberc Lung Dis. 2017 Urt 1; 21(7):784-9.

13. Prats-Uribe A, Orcau A, Millet JP, Caylà JA. Impact of socio-economic inequities on tuberculosis in a Southern European city: what is the effect of the recession? Int J Tuberc Lung Dis. 2019 Urt 1; 23(1):45-51.

14. Sohn M, Kim H, Sung H, Lee $Y$, Choi H, Chung H. Association of social deprivation and outdoor air pollution with pulmonary tuberculosis in spatiotemporal analysis. Int J Environ Health Res. 2019; 30:1-11.

15. Domínguez-Berjón MF, Borrell C, Cano-Serral G, Esnaola S, Nolasco A, Pasarín MI, Ramis R, Saurina C, Escolar-Pujolar A. Construcción de un índice de privación a partir de datos censales en grandes ciudades españolas (Proyecto MEDEA). Gac Sanit. 2008; 22(3):179-87.

16. IBM SPSS Statistics: v25.0 [Internet]. Armonk, NY: IBM Corp. 2012 [Kontsulta: 2019-07-01].

17. Joinpoint Regression Program: version 4.1.1. Rockville, MD: National Cancer Institute. 2014 [Kontsulta: 2019-07-01].

18. Kim HJ, Fay MP, Feuer EJ, Midthune DN. Permutation tests for joinpoint regression with applications to cancer rates. Stat Med. 2000 Ots 15; 19(3):335-51. Zuzenketa: 2001 Ots 28; 20(4):655.

19. Spence DP, Hotchkiss J, Williams CS, Davies PD. Tuberculosis and poverty.BMJ. 1993 Ira 25; 307(6907):759-61.

20. Baker M, Das D, Venugopal K, Howden-Chapman P. Tuberculosis associated with household crowding in a developed country. J Epidemiol Community Health. 2008; 62(8):715-21.

21. World Health Organization (editorea). A WHO / The Union monograph on TB and tobacco control: joining efforts to control two related global epidemics. Genova: WHO, 2007.

22. Rao VG, Bhat J, Yadav R, Muniyandi M, Bhondeley MK, Sharada MA, Chadha VK, Wares DF. Tobacco smoking: a major risk factor for pulmonary tuberculosis--evidence from a crosssectional study in central India.Trans R Soc Trop Med Hyg. 2014 abuz;108(8):474-81.

23. Esnaola S, de Diego M, Elorriaga E, Martín U, Bacigalupe A, Calvo M, Aldasoro E, Pardillo B. Datu garrantzitsuak 2013ko euskal osasun inkesta = Datos relevantes de la encuesta de salud del País Vasco 2013. Vitoria-Gasteiz: Osasun Saila, Azterlan eta Ikerkuntza Sanitarioko Zerbitzua = Departamento de Salud, Servicio de Estudios e Investigación Sanitaria; 2014.

24. de Vries SG, Cremers AL, Heuvelings CC, Greve PF, Visser BJ, Bélard S, Janssen S, Spijker R, Shaw B, Hill RA, Zumla A, van der Werf MJ, Sandgren A, Grobusch MP. Barriers and facilitators to the uptake of tuberculosis diagnostic and treatment services by hard-to-reach 
populations in countries of low and medium tuberculosis incidence: a systematic review of qualitative literature. Lancet Infect Dis. 2017; 17(5):e128-e143.

25. Heuvelings CC, de Vries SG, Greve PF, Visser BJ, Bélard S, Janssen S, Cremers AL, Spijker R, Shaw B, Hill RA, Zumla A, Sandgren A, van der Werf MJ, Grobusch MP. Effectiveness of interventions for diagnosis and treatment of tuberculosis in hard-to-reach populations in countries of low and medium tuberculosis incidence: a systematic review. Lancet Infect Dis. 2017; 17(5):e144-e158.

26. Morteruel M, Rodríguez-Álvarez E, Martín U, Bacigalupe A. Inequalities in Health Services Usage in a National Health System Scheme: The Case of a Southern Social European Region. Nurs Res. 2018; 67(1):26-34.

27. Carmona R, Alcázar-Alcázar R, Sarría-Santamera A, Regidor E. [Use of health services for immigrants and native population: a systematic review]. Rev Esp Salud Publica. 2014; 88(1):135-55.

28. Rodríguez-Álvarez E, Lanborena N, Borrell LN. Health Services Access Inequalities Between Native and Immigrant in a Southern European Region. Int J Health Serv. 2019; 49(1):108-26.

29. Túñez Bastida V, García Ramos, MR, Pérez del Molino ML, Lado Lado FL. Epidemiología de la tuberculosis. Med Integral 2002;39(5):172-80.

30. EAEko Zaintza Epidemiologikoaren Unitateak (editorea). Tuberkulosia EAEn 2017 [Internet]. Vitoria-Gasteiz. Osasun Saila. Osasun Publikoaren eta Adikzioen Zuzendaritza; 2018 [Kontsulta: 2019-08-24]. $\quad 17 \quad$ or. $\quad$ Eskuragarri: http://www.euskadi.eus/contenidos/informacion/informes vigilancia epidem/eu def/adjun tos/TB INFORME-CAPV-2017 eus.pdf

31. de Castro DB, de Seixas Maciel EMG, Sadahiro M, Pinto RC, de Albuquerque BC, Braga JU. Tuberculosis incidence inequalities and its social determinants in Manaus from 2007 to 2016. Int J Equity Health. 2018 abe 29; 17(187). 